\title{
For Reducing Energy Consumption in Public Transportation
}

\author{
Dr. Sara Chenche \\ LabSTIC, University of 8 Mai 1954 Guelma, Algeria \\ Assistant professor, Blida University
}

\begin{abstract}
The concept of sustainable development, applied to cities, leads necessarily to give a large place to pedestrians, to cyclists and to public transport, which returns the viability to cities, by eliminating the enlargement of cars number, urban sprawl, accidents, traffic, pollution, and especially the huge consumption of energy, caused by cars and private transport. Mobility problems (traffic, transport...) are became more and more important, to study and resolve, because of their highest consumption of energy. Our research task is focused especially on the road transport of passengers, because it is a mode very large-scale consumer of energy which is often aimed by the energy policies. This leads us to study the dependence between energy and transport, then to study the intramodality of transport by encouraging public transport. But for that the passengers leave their cars and move towards public transport, this requires the development of a high-quality public transport, which is conquering with that of private vehicles, and therefore moderate the high consumption of energy. For that one of an important problem of stop location especially in the big cities is set.
\end{abstract}

Keywords: Public transportation, Petroleum, Energy demand, Operational research.

\section{Introduction}

The energy is an essential factor in all economic activity and in the social life of countries. The high energy costs affect not only industries, but also different sectors, including transport. Logistics and storage management have already become key factors for companies to succeed in the marketplace. For companies, the major problems include: Logistics and transport management, storage, human appointment, resource allocation... The question of transport, passengers or goods, is in the middle of the big challenges of this beginning of century, solving this transportation problems is a very important economic issue for many companies.

\section{Energy balance}

Nowadays the energy became a precious commodity, on the basis of any economic success.

\section{Energy Consumption}

The high final energy consumption is divided between three major sectors of activity as follows: $44 \%$ for residential sector and agriculture, $29 \%$ for industry, and $27 \%$ for transport (See figure 1). Transport sector is the fastest growing sector in energy consumption terms, where the final energy consumption of world transport, has increased 2.2 times between 1971 and 2005 [5].

Especially in Europe, the energy absorbed by the transport sector occupies the first place with $33 \%$, followed by: industry (24.2\%), services (11\%), and agriculture (2\%) (See figure 2). Precisely in France, the share of transport in finally energy consumption reaches almost $32 \%$ in 2010 [5]. 
Fig 1. Energy consumption in the world in 2012

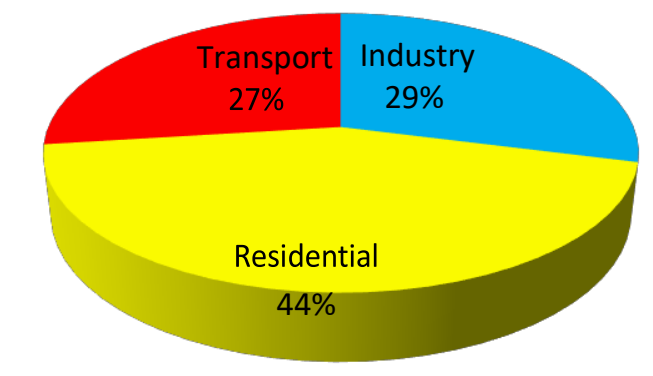

Fig 2. Energy consumption in the Europe

\section{Services Agriculture}

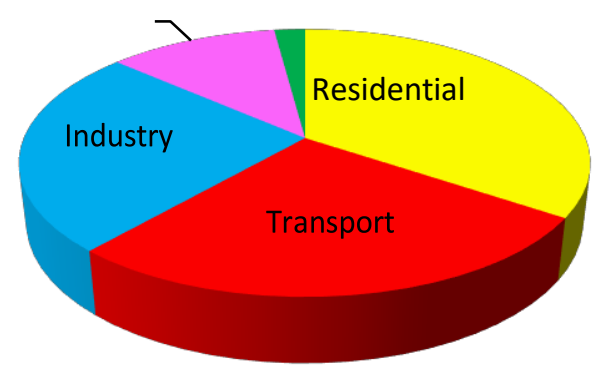

\section{Petroleum consumption in transport sector}

Hhenceforth, The petroleum is considered as the primary basic product exchanged in the world, it is also the most consumed primary energy, with a share of $36 \%$ in 2002, means around 3500 million tones (See figure 3 ) In 2012, this final consumption reached 49.2 Mtoe [1].

For the main oil-producing (petroleum- producing) countries, Saudi Arabia ranks first with $13 \%$ of total world production, followed by: the United States with 11\%, the Former USSR with 10\%, around $5 \%$ for each: Iran, Venezuela, Mexico, China and Norway. About fifteen countries participate in this assessment with few \%, such as the United Kingdom, The United Arab Emirates, Canada...etc.

The use of petroleum is essential to any economy, particularly in the transport sector, which clearly appears to be the main sector in the use of petroleum products, with a current share of $50 \%$ (See figure 3) 1 against $42 \%$ in 1973. (IFP_)

To the current time, the other energies (electricity, biomass, coal and gas) used in the transport sector occupy only a marginal place of $1.9 \%$ (IFP_) 


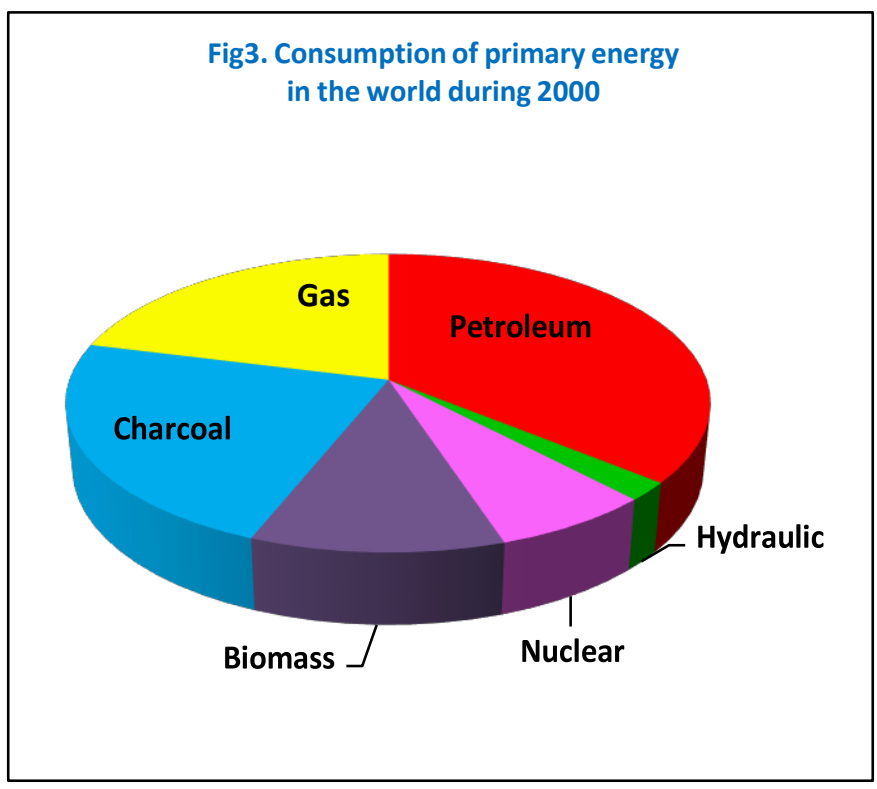

Source « Energy Balance Non-OECD Countries, 2001-2002 » IEA 2004 Edition

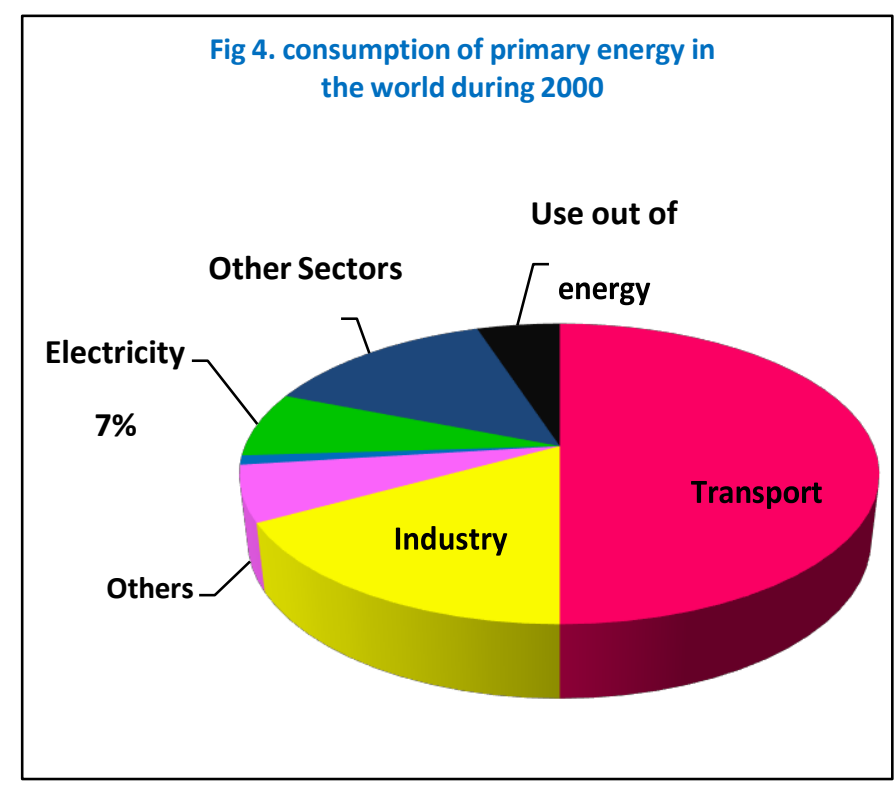

\section{Energy consumption split in transport sector in 2001}

The energy demand of the transportation sector has grown significantly during the $20^{\text {th }}$ century. The different means of transport used are: Train, Tramway, Metro, Airplane and inland waterways, but it is road transport which largely dominates the weight of energy consumption, with a share of $81 \%$ 
of transportation-related energy demand, against $29 \%$ for the consumption of other transport modes [8], divided as follows (13\% for air transport, $2 \%$ for railway and $2 \%$ for waterborne) (See figure 5).

By far, road transport is the most energy consuming and the most emitting of greenhouse gases.

More particularly, the private vehicles dominate road transport with $83 \%$, thus the private transport is the most consuming of energy and broadcasting of greenhouse gas.

In particular, the energy consumption of various transportation systems (public and private) in the Brussels-Capital Region, represented more than one fifth (means 22.3\%) of Brussels's final consumption of energy, in 2013. And it is mainly attributable to private road transport.

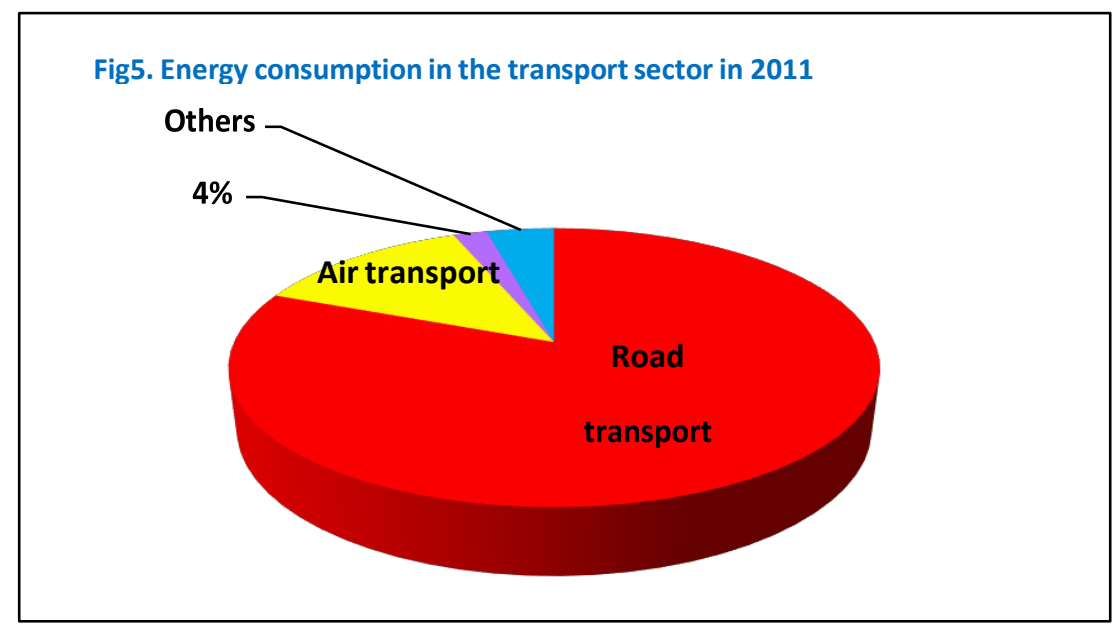

Source « World Energy Outlook 2004»

\section{Inland passenger transport}

Collective inland passenger transport is likely to be slow in term of rate progress, these transport modes (including air, rail, bus and coach) account for only $17 \%$ of passenger transport. By contrast, private passenger transport accounts for $83 \%$ of passenger traffic in 2014 [10].

In 2013, among the EU Member States, the relative importance of passenger cars transport was the highest in Lithuania, where it accounted for $91.4 \%$ of passenger transport. In most Member States the share of passenger cars transport was between 80 and $90 \%$, but it was lower in Hungry (67.5\%), and even lower in Turkey $(63.7 \%)$, hence this last has a relative importance of coaches and buses transport, of which it represented $34.9 \%$. Also, a share of more than one fifth of collective passenger transport is recorded in Hungary (22.3\%). Although, the proposition of coaches, buses and trolleybuses transport was the lowest in the Netherlands (3.3\%), and between 10 and $20 \%$ in other 17 Member states [12] (See figure 6) ${ }^{3}$. In particular, in 2014, 1000 billion passenger-kilometers were transported on French territory: 829 billion by private vehicle, 102 billion by railway, and the rest (means only 69 billion) by bus, coach or air. In 1990 the weight of private transport using private vehicle representing $83 \%$ of passengerkilometers, in 2003 it passed by a maximum with $85.3 \%$ of passenger- kilometers and then it returned and stabilized to $83 \%$ in 2014 [10]. 


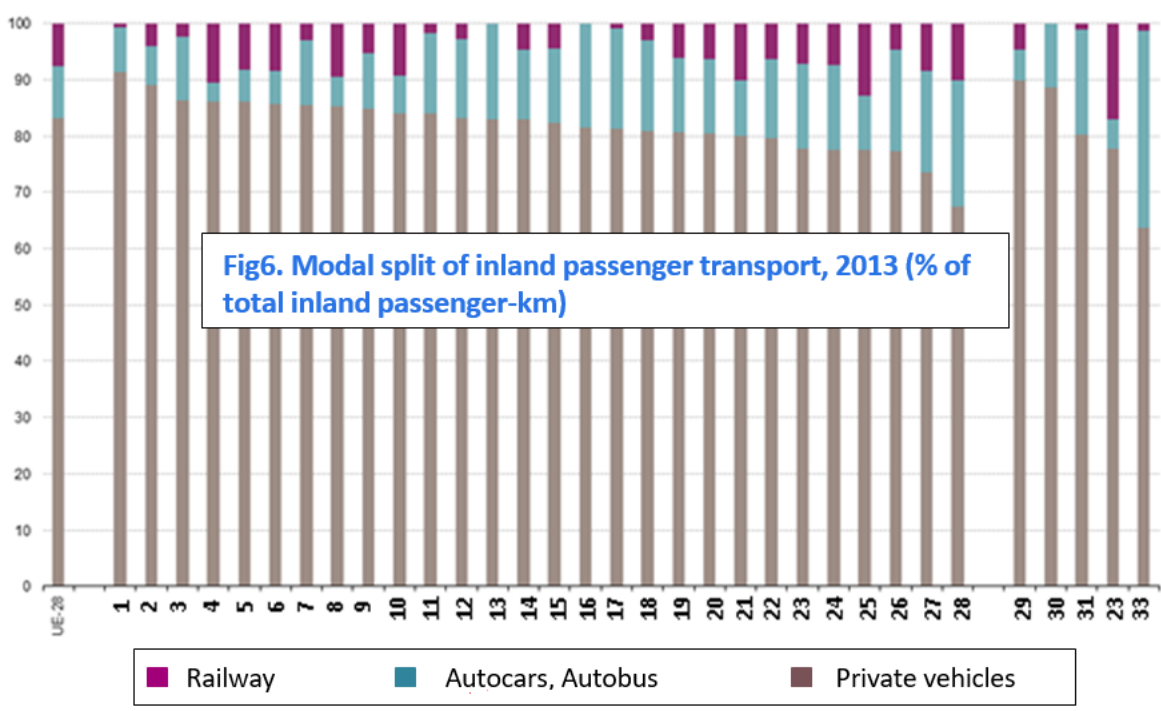

1.Lithuania 2. Portugal 3. Slovenia 4. Netherlands 5.UK 6. Germany 7. Croatia 8. France 9. Finland 10. Sweden 11. Estonia 12.Ireland 13.Malta 14. Luxembourg 15. Romania 16.Cyprus 17.Greece 18. Bulgaria 19.Spain 20.Italy 21.Denmark 22.Poland 23.Slovakia 24. Belgium 25. Austria 26.Latvia 27.Czech 28.Hungary 29.Norway 30.Iceland 31.Macedonia 32.Swiss 33.Turkey

Source Eurostat (Online data code: tran hv_psmod)

\section{For more efficient mobility}

a) The Target : $15 \%$ bicycle 2020

The Brussels charter signed on 15 May 2009 by several European cities, at the conclusion of the international conference Velo-City, sets a target of $15 \%$ of modal share bicycle to be achieved in 2020. Despite notable advances, France barely reaches $4 \%$ in 2011. For the same year, the modal share of bicycle reaches $27 \%$ in Netherlands and $18 \%$ in Denmark, in all of their respective territories [1].

\section{b) The intramodality of transport}

In the urban transport of individual, alternative modes to the individual car are recommended. The use of these alternative modes of transport is promoted in particular by the Business Travel Plans, which encourage cycling and public transport [11].

But for that the passengers leave their cars and move towards public transport, this requires the development of a high-quality public transport, which has a priority over than private vehicles. So an important problem to solve is the organization of public transport, especially in large cities.

\section{Optimization in Public Transportation}

If we pass from customers-oriented point of view, users are often dissatisfied with high costs, poor service, and failure to meet transport times (bus, train, tram, etc.). It is very difficult to satisfy the requirements of users (lower cost, better service) due to the complexity and size of planning problems. However, theory and methods of operational research make it possible to propose an adequate model of the posed problem, and in general to propose good solutions. From users-oriented point of view, we have three problems: Stop location problem [6], Delay management and pricing [9]. 


\section{Stop location problem}

The principle of stop location problem [7] is to seek to place stops along an existing bus lines. There are various demanded points by customers, and a minimum number of stops to be placed must be found, in a way to cover all demand points, knowing that a user must reside in less than a fixed distance from its demanded point (See figure 7), this distance is called covering radius ( $\mathbf{R})$. In his survey, Demetsky [2] assures that for most companies the covering radius is equal to 400 meters for public transport, and 2 kilometers for rail transport.

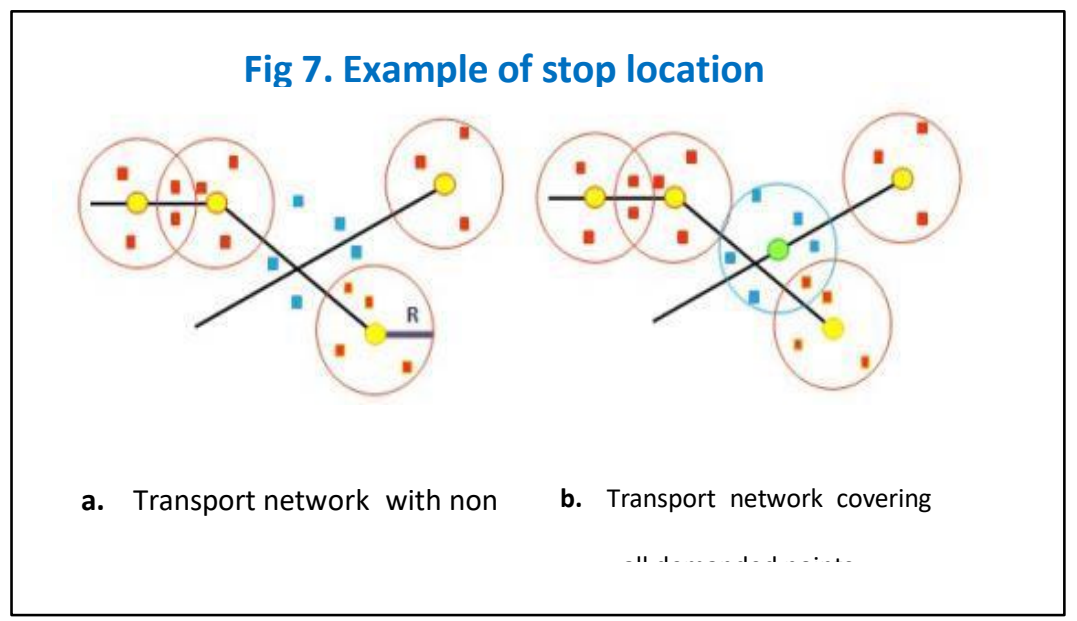

So we have two problems: the first is to maximize the accessibility to public transport network, and the second is to ensure the covering of all users attempting to use this transportation system [See 3 and 4], while at the same time ensuring the location of a minimum number of stop stations, this reduces the cost of construction run by the transport companies on one hand, and on another hand avoids the increase in total transport time, indeed, in the layout guide each additional stop increases travel time by about 2 minutes.

\section{V.Conclusion}

The energetic demand of the transportation sector, knew a real growth during the 20th century. The different forms of transport are: road, rail, air and waterborne, but it is the road transport which largely dominates the share of energy consumption, with $81 \%$ of total demand of transport-related energy. Against $29 \%$ for the consumption of other transport modes, divided as follows ( $13 \%$ for air transport, $2 \%$ for railway and $2 \%$ for waterborne). In this fact, mobility problems are became more and more important, to study and resolve, because of their highest consumption of energy. Stop location problem is an important problem to study for organizing the public transportation, so all begin with a high-quality transportation system, conquering with which of private vehicles, at this time passengers can leave their private vehicles and turn towards the public transport, and therefore moderate the high consumption of energy.

\section{References}

[1] A. Murray, R Davis, R Stimson, and L Ferreira. Public transportation access. Transportation Research, 3 :319-328, 1998.

[2] A Ruf and A Schobel. Set covering problems with almost consecutive ones property. Discrete Optimization, 15:215-228, 2004.

[3] A Schobel. Optimization in Public Transportation: Stop Location, Delay Management and Tariff Zone Design in a Public Transportation Network. Springer, 2005.

[4] Chiffre clés du transport, Edition 2016 
"www.statistiques.developpement durable.gouv.fr".

[5] D R P Gross, H W Hamacher, S Horn, and A Schobel. Stop Location Design in Public Transportation Networks: Covering and Accessibility Objectives. Springer, 2008.

[6] D R Poetranto. Stop location problem in public transportation network. Master's thesis, Technische Universit"at Kaiserslautern, 2004.

[ 7 ] D. Cochard, La transition énergétique du secteur des transports, Institut Négawatt, 2014.

[8] M J Demetsky, M Asce, and B B Lin. Bus stop location and design. Transportation Engineering Journal, $108: 313-327,1982$.

[9] M. Saadaoui and A. Boudjemil, Petroleum and transport: Dependence and consequences, Rewiew of economic research, Blida university, ISSN 1112 - 6612, 2015.

[10] R. PECCOUD, Les transports face aux défis de l'énergie et du climat, Document de travail $n^{\circ} 86$, ISSN 1954-3131, 2009.

[11] www.connaissancedesenergies.org.

[12] www.ec.europa.eu/eurostat. 